Article

\title{
Application of Terrestrial Laser Scanning to Tree Trunk Bark Structure Characteristics Evaluation and Analysis of Their Effect on the Flow Resistance Coefficient
}

\author{
Tomasz Kałuża ${ }^{1}$, Mariusz Sojka ${ }^{2}$, Paweł Strzeliński ${ }^{3}$ and Rafał Wróżyński ${ }^{2, *}$ \\ 1 Department of Hydraulic and Sanitary Engineering, Poznań University of Life Sciences, Piątkowska 94, \\ 60-649 Poznań, Poland; tomasz.kaluza99@gmail.com \\ 2 Institute of Land Improvement, Environmental Development and Geodesy, Poznań University of Life \\ Sciences, Piatkowska 94, 60-649 Poznań, Poland; masojka@up.poznan.pl \\ 3 Department of Forest Management, Poznań University of Life Sciences, Wojska Polskiego 71C, \\ 60-625 Poznań, Poland; strzelin@up.poznan.pl \\ * Correspondence: rafwro@up.poznan.pl; Tel.: +48-0-61-846-6418
}

Received: 30 April 2018; Accepted: 5 June 2018; Published: 8 June 2018

\begin{abstract}
The paper presents an original method for the evaluation of bark structure characteristics of tree trunks on the basis of terrestrial laser scanning data. Measurements testing the method proposed were performed in laboratory conditions for trunks of pine (Pinus sylvestris L.) and oak (Quercus robur L.). The laser scanner used was a FARO Focus 3D. The scanning was carried out in two variants for natural trunks (variant I: samples Oak-I, Pine-I) and for trunks wrapped in foil (variant II: samples Oak-II, Pine-II). The point clouds obtained were combined into a three-dimensional (3D) model, filtered, and exported to the *.xyz format in SCENE (v. $5 \times$ ) software provided by FARO. For calculation of the bark structure characteristics the geoprocessing Tree Trunk Bark Structure Model (TTBSM) operating in the ArcGIS environment was developed. The mean bark height factor (BHF) of the natural pine and oak tree trunks was calculated to be $0.39 \mathrm{~cm}$ and $0.37 \mathrm{~cm}$, while the values for the trunks wrapped in foil were $0.27 \mathrm{~cm}$ and $0.25 \mathrm{~cm}$, respectively. The $B H F$ of the tree trunks wrapped in foil varied in the range $0.26-0.28 \mathrm{~cm}$ and $0.24-0.26 \mathrm{~cm}$ for pine and oak, respectively, while for the natural tree trunks the range was $0.38-0.46 \mathrm{~cm}$ and $0.35-0.38 \mathrm{~cm}$ for pine and oak, respectively. The effect of BHF on the flow resistance was evaluated in a measuring trough and proved to be significant. The coefficient of flow resistance was on average $20 \%$ higher for the natural tree trunks than for those foil-wrapped.
\end{abstract}

Keywords: laser scanning; tree trunk bark characteristics; tree trunk flow resistance; laboratory studies

\section{Introduction}

Many authors have carried out research on the impact of vegetation on flow conditions in open channel flow. The studies concern derivation of theoretical principles of the mathematical modeling of the phenomenon [1-5], numerical modeling with models of varying complexity [6-8], flume experiments to verify models of vegetation roughness [9-11], and in situ floodplain roughness estimations [12]. Remote sensing methods were used to acquire data used in hydraulic modeling [13].

The roughness calibration of floodplains and channels is an important issue in flood studies [14]. Riparian vegetation plays a crucial role affecting the floodplain hydraulic roughness [15]. Vegetation roughness, and more specifically forest roughness, is a necessary component in more accurate determination of flood dynamics [16]. Tree trunks are major contributors to the roughness coefficient in 
a densely wooded floodplain. Petryk and Bosmajian [17] have developed a method for determination of the roughness coefficient on the basis of the vegetation density. Trees density can be determined by measuring the number of trees and trunk sizes in a representative-sample area [18]. From the hydrological point of view, measurement of canopy structure must be nondestructive and applicable over a broad area to allow investigation of seasonal fluctuations [19].

The floodplain drag coefficient sums up pressure and friction drag. The pressure, or form drag, is caused by the difference between the high pressure upstream and low pressure downstream of an element [20]. For open-channel flow the friction factor $f_{p}$ for riparian vegetation is defined as:

$$
f_{p}=\frac{4 \cdot h \cdot d_{p}}{a_{x} \cdot a_{y}} \cdot C_{d}
$$

where $h$ is the flow depth $(\mathrm{m}), d_{p}$ is the diameter of the plant $(\mathrm{m}), a_{x}$ is the longitudinal distance between the plants (m), $a_{y}$ is the lateral distance between the plants $(\mathrm{m})$, and $C_{d}$ is the plants' drag coefficient.

The drag coefficient $C_{d}$ depends on the separation characteristics of the cylinder boundary layer and is a function of the cylinder Reynolds number:

$$
\operatorname{Re}=\frac{u \cdot d_{p}}{v}
$$

where $u$ denotes mean velocity and $v$ denotes the fluid kinematic viscosity (e.g., [21]).

This type of formulation was originally derived for rigid cylinders simulating tall trees, but its use has been extended to other types of vegetation. However, for natural plants the determination of projected area and drag coefficient is difficult. The hydraulic characteristics $d_{p}, a_{x}$, and $a_{y}$ are determined on the basis of field measurements in the area of the water flow. Floodplains and riparian zones of rivers and streams are usually covered by groups of trees or bushes.

Estimation of the flow resistance of trees $F_{d}$ is complex due to the variability in tree morphology [22]. In fluid mechanics, the drag force, which acts on a surface area $A_{d}$ measured perpendicular to the direction of the flow, may be defined as:

$$
F_{d}=\frac{1}{2} \cdot \rho \cdot C_{d} \cdot A_{d} \cdot u^{2}
$$

where $\rho$ is the density of the fluid $\left[\mathrm{kg} \cdot \mathrm{m}^{-3}\right], A_{d}$ is the vegetal area $\left(A_{d}=h \cdot d_{p}\right)\left(\mathrm{m}^{2}\right)$.

The main basis for hydraulic calculations of the river flow, where the structure of high vegetation is taken into account, is that water flow resistance is the same as vegetation resistance, which occur when water overflows regularly distributed vegetation with averaged geometric parameters and averaged effect of roughness of plants on the coefficient $C_{d}$. It is important to correctly determine these parameters.

At present to describe the canopy structure of flood valleys satellite multispectral data [15] and airborne (ALS) [23-25] and terrestrial laser scanning data (TLS) are used [26]. Laser scanning is an active remote-sensing technique, which provides high-resolution spatial data [27]. ALS data were used to explore the tree morphometric properties from riparian zones such as tree position, tree height, trunk location, and tree spacing [28]. Methods based on ALS data do not allow detailed analysis of tree trunk and branch parameters. Nowadays TLS technique is widely used in forestry applications $[29,30]$. TLS can produce high-resolution three-dimensional point clouds over scales of meters to kilometers with centimeter or sub-centimeter precision on geometric parameters of trees [31,32]. Methods based on TLS data have been used for automatic measurement of forest inventory attributes [27,33]. Numerous studies can be found in literature on calculation of the diameter at breast height $(D B H)$, the height of the tree, the volume of wood, stem ovality, structure, and damage of the bark, tree topology, branch angles, and diameters [34,35]. Othmani et al. [30,36], Brolly and Király [27], and Lin and Herold [37] have confirmed the possibility of identification of tree species using TLS data on the basis of 3D bark 
texture analysis. It has been proven that TLS is capable of fulfilling such tasks as: retrieval of leaf area density [38], derivation of vertical crown profile [39], and estimation of above-ground biomass [40]. Sioma et al. [41] were used 3D vision system to characterizing spatial patterning of bark texture.

TLS is used for the purpose of extracting canopy parameters relevant for parameterization of the flow resistance equations [26]. Laser scanning is an efficient technique to obtain data on the scale of a single tree $[27,28]$. Beside TLS, a commonly used method is Structure from Motion, which can be used to make 3D models from photographs [42] or video frames [43]. Considering the variety of tree trunk surfaces, it is very important to determine the drag characteristics of real tree trunks with various barks to a high accuracy. Estimation of the drag coefficient of a real tree considering the vertical stand structure of the trunk, branches, and leaves has been studied by Tanaka et al. [44]. According to these authors, reliable determination of the vegetation flow resistance requires the millimeter scale resolution that can be provided by terrestrial laser scanning $[45,46]$. Roughness of the tree trunk surface is known to affect their flow resistance; however, hitherto its effect has been neglected and $C_{d}$ values the same as for smooth cylinders have been applied. The progress in remote sensing technology has provided an opportunity for detailed studies taking into account the tree bark structure.

The aims of the study were: (i) to develop a model (Tree Trunk Bark Structure Model-TTBSM) for supporting the calculations of tree trunk bark characteristics on the basis of the data from terrestrial laser scanning in the ArcGIS 10.5 (ESRI Inc., Redlands, CA, USA) environment; (ii) to analyze the effect of bark structure on the drag force in a forested zone.

\section{Materials and Methods}

\subsection{Characterization of the Tree Trunks Used}

The effect of bark structure of tree trunks on the flow resistance coefficient was evaluated for the trunks of Scots pine (Pinus sylvestris L.) and common oak (Quercus robur L.). Scots pine is the most common tree species in Polish forests, representing over $58.2 \%$ of trees in forested areas. Pines often grow on sandy soil in alluvial river valleys. The second most frequent tree species in Polish forests is common oak, with a frequency of $7.7 \%$. Because of its ecological demands this species grows in wet and marshy habitats. The measurements were performed for freshly cut bottom fragments of tree trunks of about $0.2 \mathrm{~m}$ in diameter and $0.5 \mathrm{~m}$ in height. The tree trunk samples were weighed and their diameters and circumferences were measured (Table 1).

Table 1. Basic parameters of tree trunk samples used for measurements.

\begin{tabular}{cccc}
\hline \multirow{2}{*}{ Parameters } & Units & \multicolumn{2}{c}{ Tree Species } \\
\cline { 3 - 4 } & & Pine & Oak \\
\hline Height & $(\mathrm{m})$ & 0.5 & 0.5 \\
Weight & $(\mathrm{kg})$ & 9.3 & 11.2 \\
\hline Circumference & & & \\
\hline bottom & $(\mathrm{m})$ & 0.60 & 0.67 \\
mid & $(\mathrm{m})$ & 0.62 & 0.68 \\
top & $(\mathrm{m})$ & 0.56 & 0.64 \\
\hline Diameter & & & \\
\hline bottom & $(\mathrm{m})$ & 0.190 & 0.205 \\
top & $(\mathrm{m})$ & 0.185 & 0.210 \\
\hline
\end{tabular}

\subsection{Tree Trunk Scanning}

The surfaces of the tree trunks were subjected to scanning. To ensure their stability in the process they were attached to a special board and set on a table (Figure 1). Around the tree trunk to be scanned four white reference balls were placed (K1-K4) that permitted later combination of the scans into a 
single 3D model. Each fragment of the tree trunk was scanned from three sites localized in such a way that a 3D model of the trunk could be obtained. The scanner was positioned at a distance of 2.2-2.5 $\mathrm{m}$ from the trunk. The positions of the reference balls with respect to one another and to the trunk were unchanged.

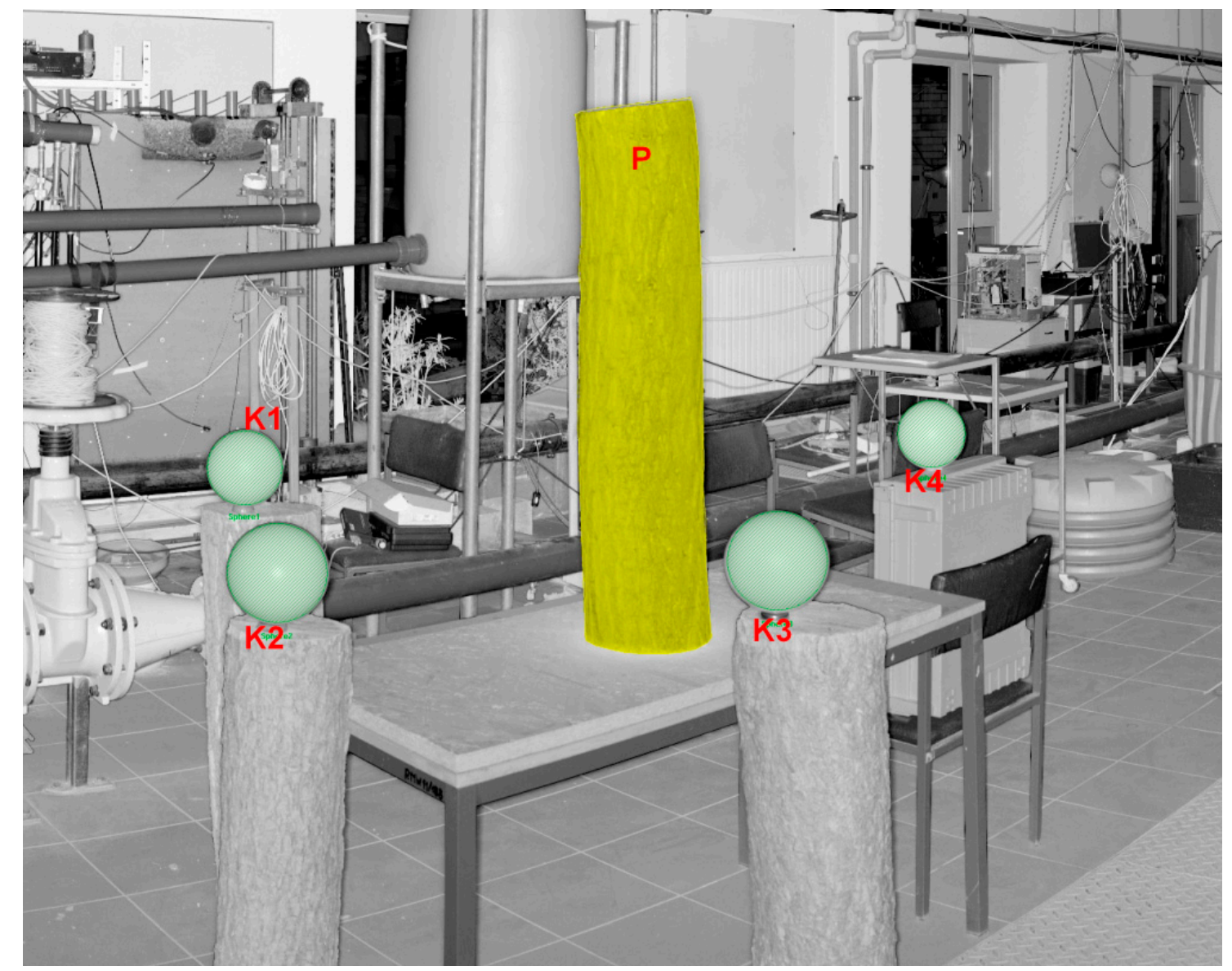

Figure 1. Scan of the trunk (P) with the four reference balls (K); photogrammetric image of point cloud intensity.

In order to evaluate the effect of tree trunk bark structure on the flow resistance, the scanning was performed in two variants. At first the tree trunks were wrapped up with a stretch foil and scanned. The applied foil was made of stretchable polyethylene of low density (LLDPE). The foil had a thickness of $23 \mu \mathrm{m}$ and stretch of $150 \%$. Due to its elasticity and stretching during wrapping, the foil adhered very tightly to the trunk thus eliminating microrelief of the trunk bark. Foil wrapped trunks simulated smooth trunks without bark. In the second variant of the experiment the tree trunks in their natural form-without foil-were scanned. This sequence of measurements was chosen on purpose to minimize disturbances to the trunks' positions as the procedures of wrapping carry greater risk of disturbance than the unwrapping. The scanner used was FARO Focus 3D (Lake Mary, FL, USA); its parameters are given in Table 2.

The scanner settings were: resolving power $\frac{1}{4}$, quality $4 \times$, rate 122 thousand points s ${ }^{-1}$, vertical range 10-25 degrees, horizontal range 0-60 degrees. The used scanner settings allowed point clouds with spatial resolution of 50 points $/ \mathrm{cm}^{2}$ to be obtained. 
Table 2. Scanner specification

\begin{tabular}{cc}
\hline Ranging Unit & \\
\hline Range & $0.6-120 \mathrm{~m}$ \\
Measurement speed & $\begin{array}{c}122,000-976,000 \mathrm{points} \mathrm{s}^{-1} \\
\pm 2 \mathrm{~mm} \text { at } 10 \mathrm{~m}\end{array}$ \\
\hline Ranging error & \\
\hline Laser (Optical Transmitter) & $20 \mathrm{~mW}$ \\
\hline Laser power (cw Ø) & $905 \mathrm{~nm}$ \\
Wavelength & $0.19 \mathrm{mrad}\left(0.011^{\circ}\right)$ \\
Beam divergence & $3.0 \mathrm{~mm}$, circular \\
Beam diameter at exit & \\
\hline Deflection Unit & $305^{\circ}$ \\
Vertical field of view & $360^{\circ}$ \\
Horizontal field of view & $0.009^{\circ}\left(40,9603 \mathrm{D} \mathrm{pixel} \mathrm{on} 360^{\circ}\right)$ \\
Vertical step size & $0.009^{\circ}\left(40,9603 \mathrm{D} \mathrm{pixel} \mathrm{on} 360^{\circ}\right)$ \\
Horizontal step size & $5820 \mathrm{rpm}$ or $97 \mathrm{~Hz}$ \\
\hline Max. vertical scan speed &
\end{tabular}

\subsection{Data Preprocessing}

The point clouds obtained from individual scans were combined in a single 3D model using the SCENE (v. 5.0) software from FARO. The SCENE software was necessary for reading in the scan files, for detection of reference balls and combination of the scans in one 3D model. Then the models were subjected to preliminary filtration and the scanning area was reduced to the trunk. Finally the point clouds obtained were exported to a file of *.xyz format, containing information on the 3D coordinates of each point and on the intensity of reflection recorded as grades of grey.

\subsection{Data Processing-Calculation of Tree Trunk Bark Characteristics}

In order to calculate bark characteristics of the tree trunks GIS tools were used. The idea was to use similar techniques as in physiography studies to describe terrain roughness with Digital Terrain Models but on the micro scale. In order to achieve this, the input data, in the form of point clouds of scanned tree trunks, should be unwrapped to a $2.5 \mathrm{D}$ surface. The TTBSM was created to make this time-consuming process fully automated. The scheme of the model processing is shown in Figure 2.

The first step was to import the scanned tree trunk point cloud data in .XYZ format. The next step was to unwrap the point cloud into a 2.5D form. The transformations of point clouds making 3D models of tree trunks $(X, Y, Z)$ to the calculation form $\left(X^{\prime}, Y^{\prime}, Z^{\prime}\right)$ were performed according to Formulas (4)-(6).

$$
\begin{gathered}
X_{i}^{\prime}=\frac{2 \pi \cdot \alpha_{i} \cdot \overline{Z_{i}^{\prime}}}{360} \\
Y_{i}^{\prime}=Z_{i} \\
Z_{i}^{\prime}=\sqrt{\left(X_{i}-X_{C}\right)^{2}+\left(Y_{i}-Y_{C}\right)^{2}}
\end{gathered}
$$

As the symmetry axis of the tree trunk could not be described by a straight line parallel to the $\mathrm{Z}$ axis, the point clouds were divided into segments $5 \mathrm{~cm}$ in height and treated separately. For each segment the axis of symmetry $C$ was defined and its coordinates were read in $\left(X_{C}, Y_{C}\right)$. Then, the lengths of the sections $\mathrm{C}-\mathrm{P}$ that are the transformed values of the coordinate $Z_{i}^{\prime}$ and the angles $\alpha_{i}$ made by the sections with the OX axis were calculated.

The transformed point clouds were used to make digital models of tree trunk surfaces in the TIN (Triangulated Irregular Network) format using the program ArcGIS with the 3D Analyst extension. On the basis of the digital models of surfaces of natural and foil-wrapped tree trunks, made for segments $0.05 \mathrm{~m}$ in height, the average slope, standard deviation of slope and ratio of 2D to 3D area 
were calculated using the standard tools available in the ArcGIS environment. The additional bark characteristics used-average absolute slope, standard deviation of slope, and the ratio of 2D to 3D area-are commonly used for description of surface morphometric characteristics. Average absolute slope is the arithmetic average of the absolute value of slope calculated in $0.05 \mathrm{~m}$ segments of tree trunk. Standard deviation of slope is the sum of the squared deviation of each individual slope rate from the average absolute slope. The 2D area is calculated from a top orthographic view and 3D area takes into account 3D characteristics of the surface. A 3D surface with many peaks and valleys will have a larger $3 \mathrm{D}$ surface area than a plan view representation of the same area in $2 \mathrm{D}$. It was assumed that the same parameters could be used for characterization of tree trunk bark surfaces. The parameters used in this work results from the ASME B46.1-1995 [47].

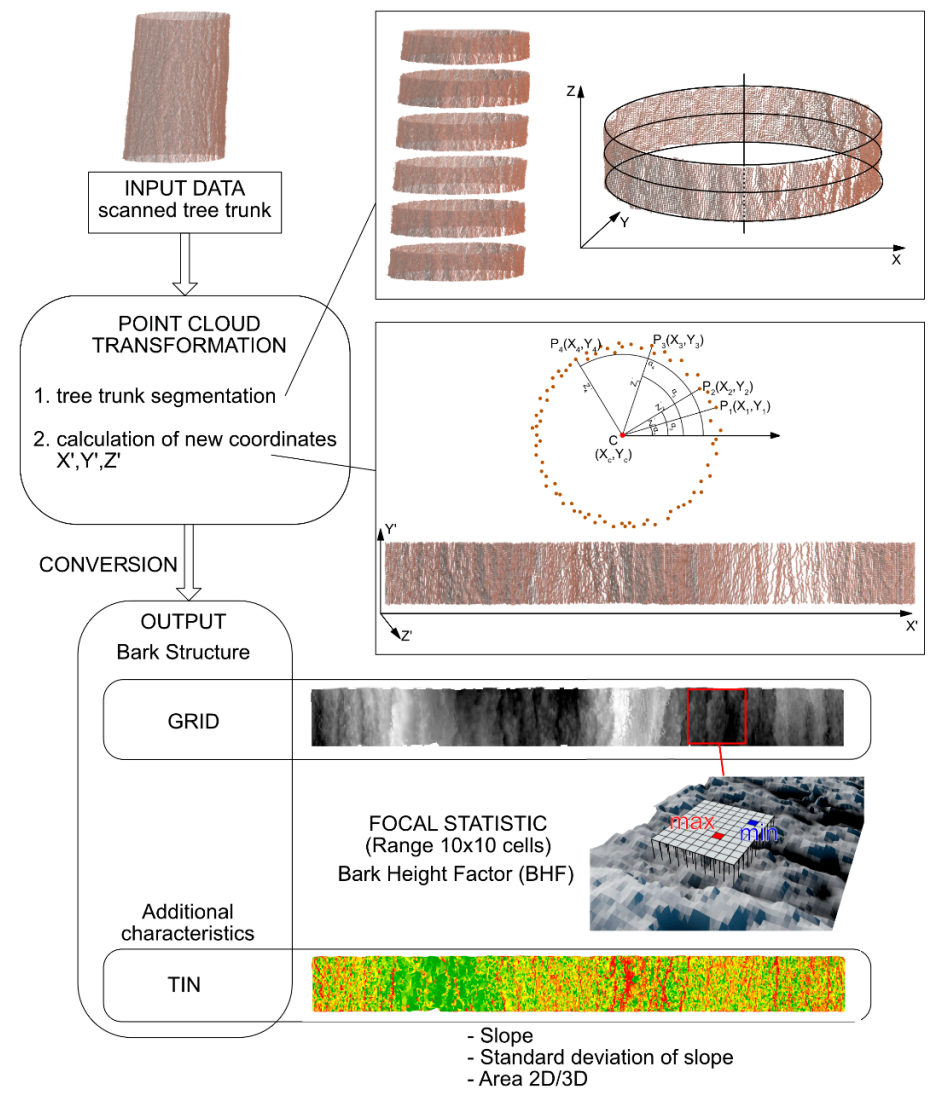

Figure 2. The scheme of TTBSM processing.

In order to calculate the bark height factor $(B H F)$, the tree trunk surface models were converted from the TIN to GRID format assuming the cell size of $0.001 \mathrm{~m}$. The Focal Statistics modulus was used with the function Range within a square window of 10 by 10 cells (unit area). The Range value describes the Maximum Height of the unit area $R_{t}$, which is calculated as the vertical distance between the highest and lowest points of the unit area. The BHF in this study is described as average maximum height, which is calculated as the average of the successive maximum height values of $B H F_{i}$ calculated over the $0.05 \mathrm{~m}$ tree trunk segments.

$$
B H F=\sum_{i=1}^{N} B H F_{i}
$$

where $i$ denotes the number of unit area in $0.05 \mathrm{~m}$ tree trunk segments.

To assess the differences between $B H F$, average absolute slope, standard deviation of slope, and the ratio of 2D to 3D area for natural tree trunks and tree trunks wrapped in foil a nonparametric Kruskal-Wallis test $(\mathrm{K}-\mathrm{W})$ was performed. The Kruskal-Wallis rank test was employed for the 
verification of the hypothesis on significance of differences between medians of $B H F$ and other bark characteristics.

\subsection{Evaluation of the Effect of Tree Trunk Bark Structure on Flow Resistance}

Measurements were carried out in a laboratory in a hydraulic trough with $12 \mathrm{~m}$ in length, $0.47 \mathrm{~m}$ in width, and $0.9 \mathrm{~m}$ in height. The trough was flooded with water in a closed system with the maximum flow rate of $120 \mathrm{~L} \cdot \mathrm{s}^{-1}$. The trough filling was controlled by a lid at one end of the trough. The measuring system was equipped with an electromagnetic flow meter and an electronic sensor of the water level. In the trough there was a dynamometric platform connected to a tensometric sensor capable of measuring tangential and stretching forces in the range up to $0.05 \mathrm{kN}$ (Figure 3). Moreover, water temperature and speed of water reaching the tree trunk were measured using a micro ADV probe. Measurements were made for 11 different mean flow values from the range 0.1-0.7 $\mathrm{m} \cdot \mathrm{s}^{-1}$ for two variants of the experiment: for the natural trunks and for the trunks wrapped in foil. Each measurement was repeated twice.

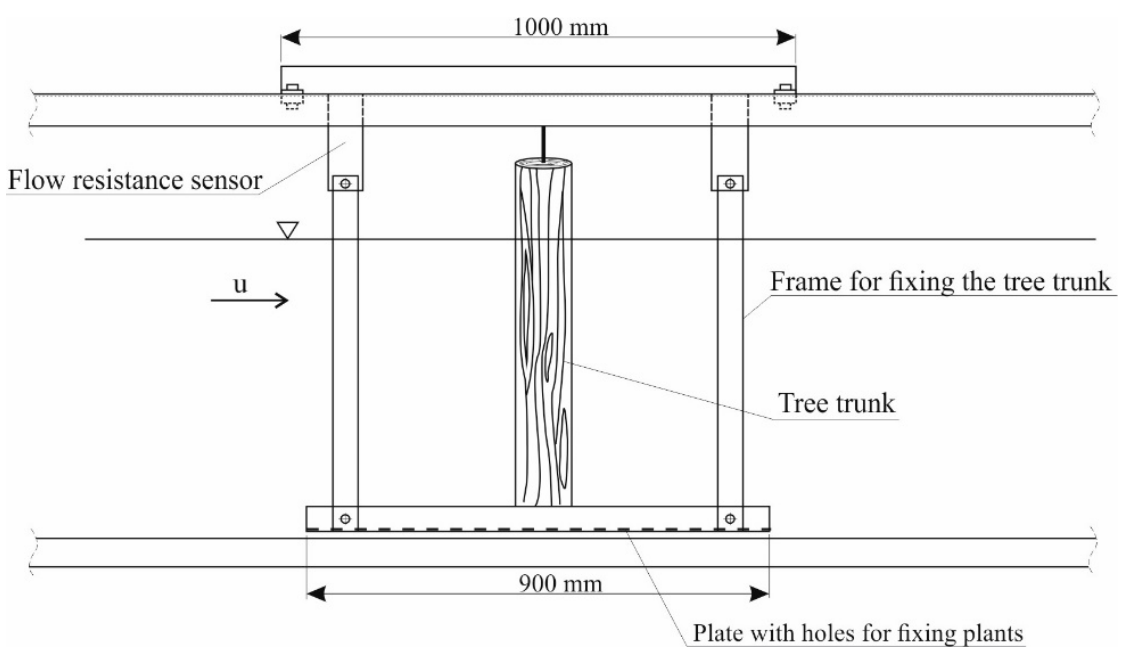

Figure 3. Scheme of the measuring setup and view of the hydraulic trough.

The results were analyzed for a relationship between the coefficient of flow resistance of particular tree trunk samples and the parameters used for characterization of their surfaces: average slopes, standard deviations of the slopes, ratio of $2 \mathrm{D}$ to $3 \mathrm{D}$ area, and BHF.

\section{Results}

\subsection{Bark Characteristics of Tree Trunks}

The point clouds obtained from the scans made in laboratory conditions were combined into 3D models (Figure 4).

In the next step, using the TTBSM model, the point clouds were divided into segments $0.05 \mathrm{~m}$ in width, resulting in eight segments which were used in the analysis (Figure 5A). The transformed point clouds were the input data for generation of digital models of the tree trunk surfaces in the TIN format (Figure 5B). The use of the TIN model for the calculations followed from the necessity of preservation of the original data from the scans. Using the standard tools available in the ArcGIS environments, the average slope, standard deviation of slope, ratio of $2 \mathrm{D}$ to $3 \mathrm{D}$ area, and $B H F$ (Figure 5C) were calculated. 


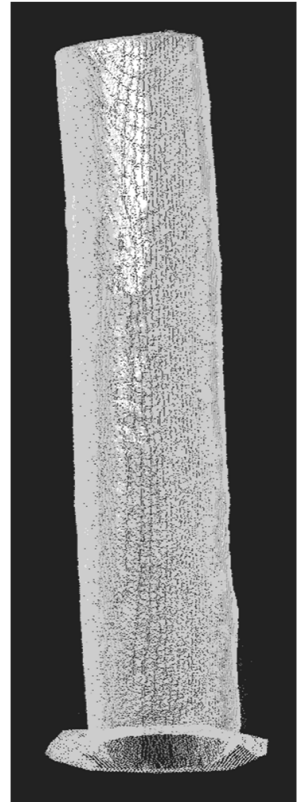

(A)

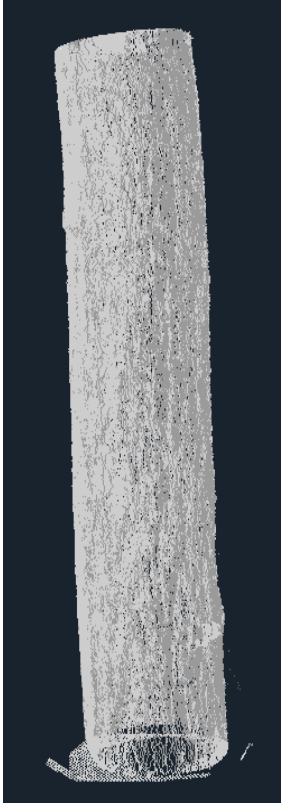

(B)

Figure 4. Example of 3D model of the oak tree trunk, (A) wrapped in foil; (B) natural.
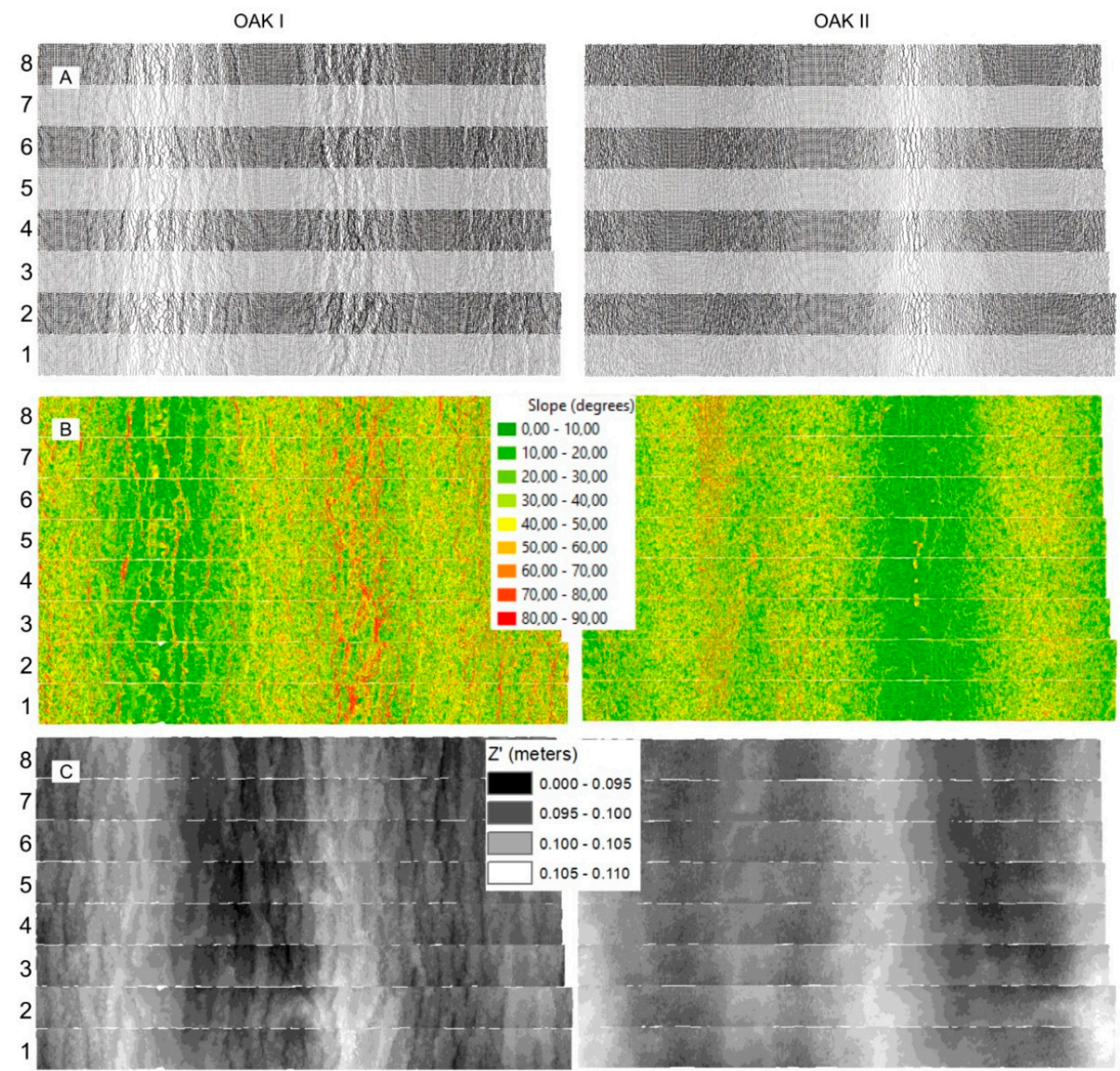

Figure 5. (A) transformed point cloud; (B) triangulated irregular network; (C) Bark height factor (BHF) of Oak I and Oak II samples. 
Analysis of the surface sculpture of the natural tree trunks (Oak I, Pine I) and the foil-wrapped corresponding trunks (Oak II, Pine II) has shown the diversity of the surface structures (Table 3). The slopes measured for the natural tree trunks were higher than for the samples foil-wrapped and varied from 31.6 to $34.5^{\circ}$ and 25.7 to $27.5^{\circ}$, respectively. For the oak and pine tree surfaces the average slopes were similar and equal to $32.2^{\circ}$ and $32.6^{\circ}$, respectively. Lower roughness of the tree trunks foil-wrapped is also indicated by the analysis of average standard deviations equal to 15.7 and 15.9 for pine and oak tree trunks, respectively. The above results were confirmed by analysis of the ratio of $2 \mathrm{D}$ to $3 \mathrm{D}$ areas. For the natural tree trunks the average $2 \mathrm{D}$ to $3 \mathrm{D}$ area ratio was lower and close to 0.70 , while for the trunks foil-wrapped this ratio was 0.81 . Similarly, as for the slopes and their standard deviations, the ratios of 2D to 3D area of the trunks foil-wrapped were similar. For the natural tree trunks (without foil), the average BHF of the pine trunk was greater, $0.41 \mathrm{~cm}$, while that of the oak trunk was $0.37 \mathrm{~cm}$.

Table 3. Characteristics of the surfaces of tree trunks studied.

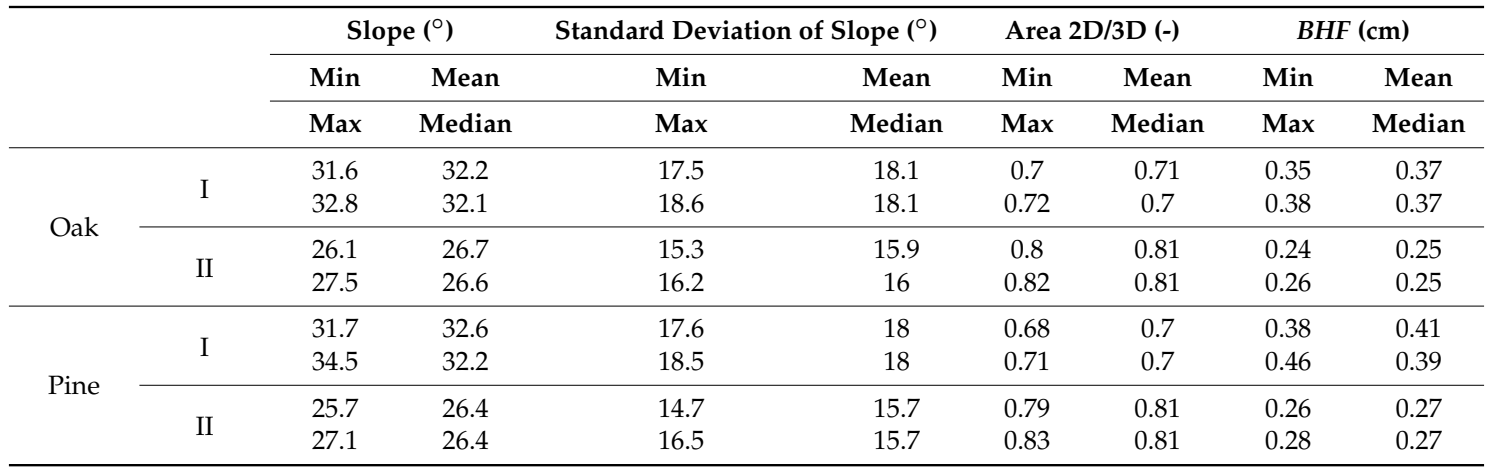

Analysis of bark structure characteristics of the foil-wrapped tree trunks, performed over segments of $0.05 \mathrm{~m}$, revealed the greatest differences in the bottom parts of the trunks. The analysis indicate the greatest differences between the average slopes (Figure 6A) and 2D to 3D area ratios (Figure 6C) in segment no 1 and slope standard deviations in segments no 1, 2 and 5 (Figure 6B). The analysis of BHF for both foil-wrapped tree trunks indicate that for pine the values were slightly higher than in oak from 0.01 to $0.03 \mathrm{~cm}$. The greatest differences were observed in segment no 2 (Figure 6D). The analysis of pine and oak trunks indicate the greatest differences between average slope, $2 \mathrm{D}$ to $3 \mathrm{D}$ area ratio and $B H F$ were observed in their bottom segments no 1 and 2 . The most uniform was the surface of the oak tree trunk, characterized over the whole length by the lowest variation in the slopes, $2 \mathrm{D}$ to $3 \mathrm{D}$ area ratios and BHF (Figure 6). For pine tree, the greatest BHF was noted in the bottom part of the trunk. The 2D to 3D area ratios for oak tree trunks proved that the difference between $2 \mathrm{D}$ and 3D area was up to $45 \%$ (percentile of $75 \%$ ) for the natural tree trunk and $28 \%$ for the trunk wrapped in foil. For the pine tree the analogous difference was $48 \%$ and $26 \%$ for the natural and foil-wrapped trunk, respectively. For the tree trunks wrapped in foil, the $2 \mathrm{D} / 3 \mathrm{D}$ area ratio in the percentile range $25-75 \%$ varied from 0.72 to 0.96 , while for the natural trunks it varied from 0.55 to 0.93 (Figure 7A). The slope values in the percentile range $25-75 \%$ varied from 23 to $55^{\circ}$ for the natural tree trunks, while for the foil-wrapped trunks the values were lower and varied from 17 to $43^{\circ}$ (Figure 7B). The Kruskal-Wallis rank test indicate the statistical significant differences between medians of BHF and other bark characteristics for pine and oak natural and wrapped in foil trunks. Differences were significant at level of 0.05 . 


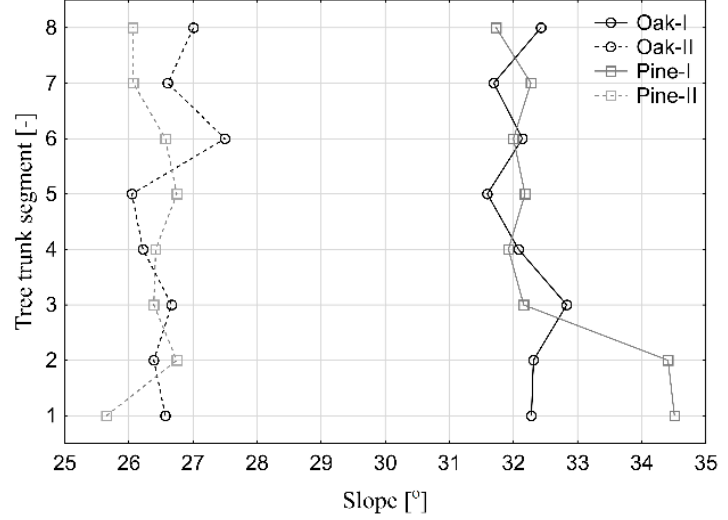

(A)

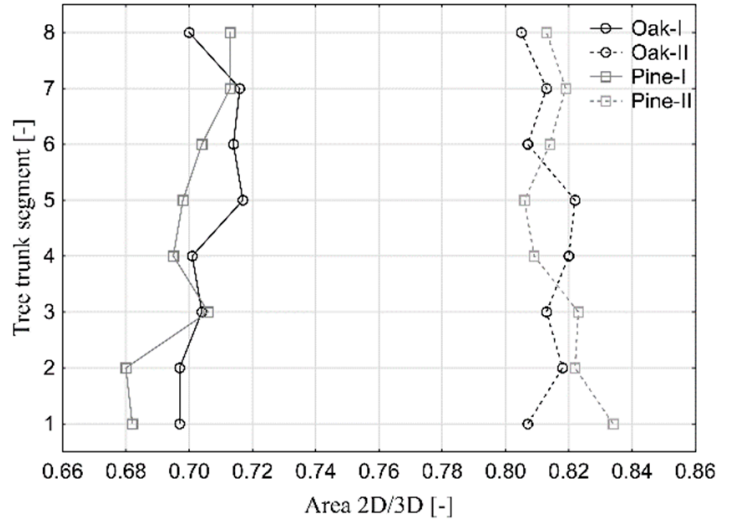

(C)

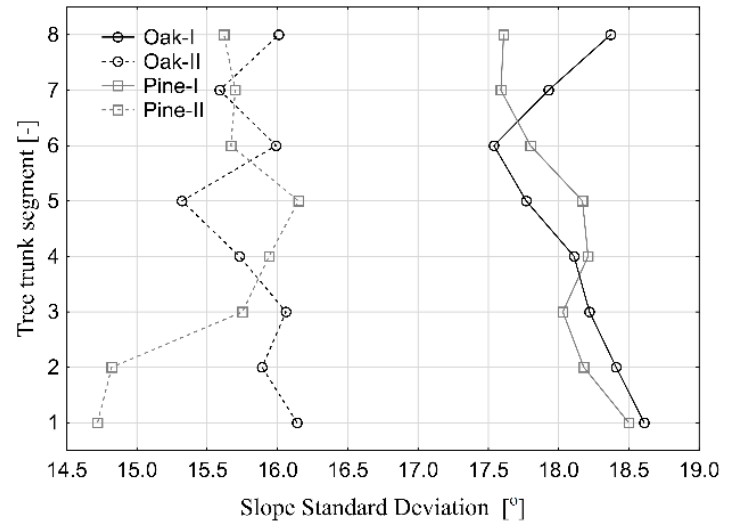

(B)

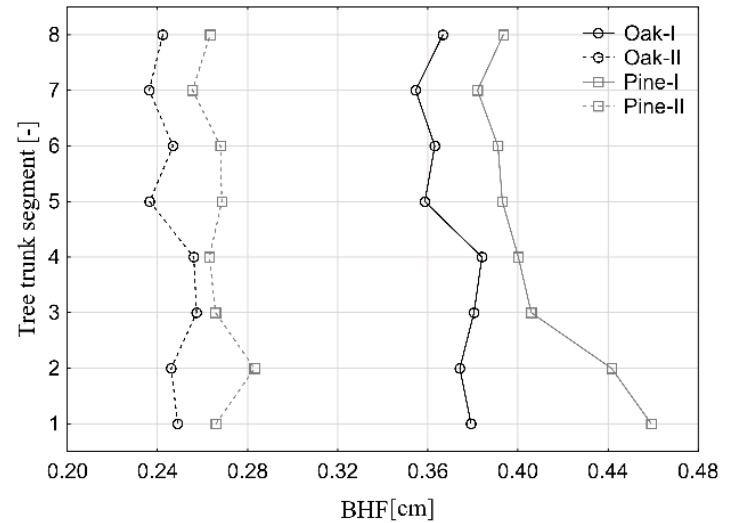

(D)

Figure 6. Changes in the slope (A); standard deviation of slope (B); 2D to 3D area ratio (C) and BHF (D) along the trunks of oak and pine trees.

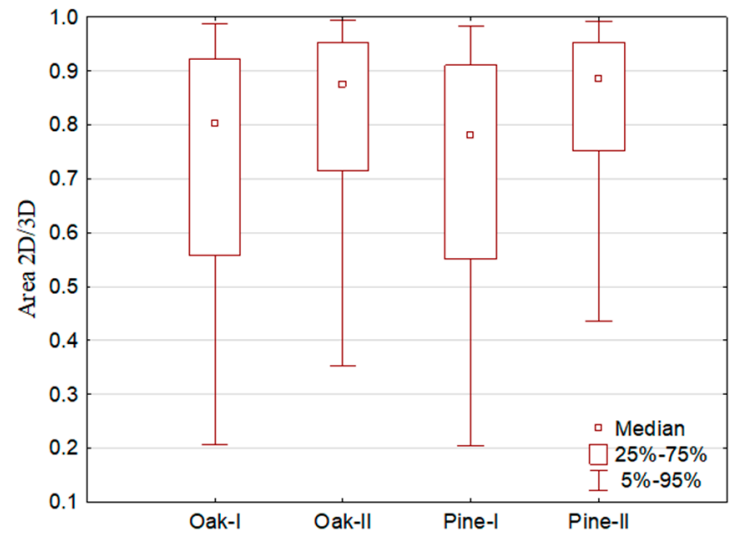

(A)

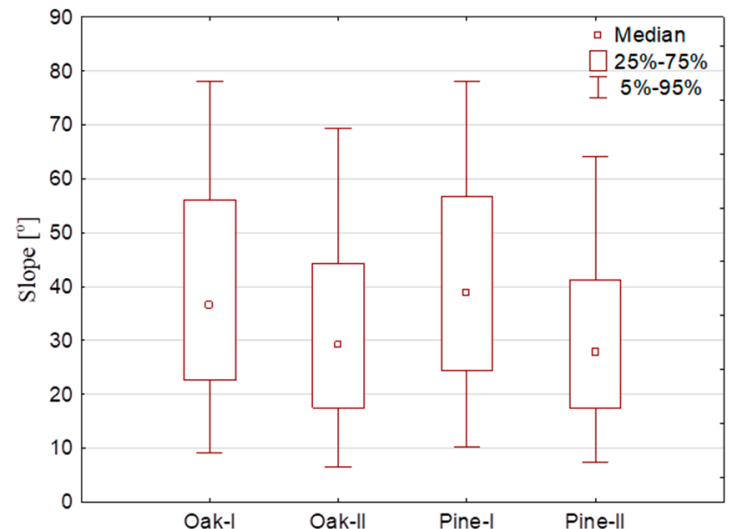

(B)

Figure 7. Statistical analysis of 2D/3D area ratio (A) and slope (B) for oak and pine tree trunks.

\subsection{Relation between Flow Resistance of Trees and Bark Structure}

On the basis of measurements performed in the hydraulic trough, the values of flow resistance coefficient $\mathrm{Cd}$ were calculated from Equation (3). The measured parameters included: resisting force on flow around a tree trunk $F_{d}$, tree trunk diameter $d_{p}$, depth of immersion $h$, speed of water approaching the tree trunk, and water temperature. The resisting force $F_{d}$ was calculated as the arithmetic mean from the results. The average tree trunk diameter $\mathrm{dp}$ was the mean value from diameter measurements 
at five heights of $0 \mathrm{~m}, 0.1 \mathrm{~m}, 0.2 \mathrm{~m}, 0.3 \mathrm{~m}$, and $0.4 \mathrm{~m}$. The depth of immersion $h$ was the distance between the dynamometric plate on which the tree trunk was set and the water level measured using a micrometric pin. The speed of water approaching a tree trunk $u$ was calculated as the mean value obtained in analysis of speed values distribution. The water temperature during the experiment was $18.10^{\circ} \mathrm{C}$. On the basis of the results of measurements substituted into Equation (2), the Reynolds number $R_{e}$ was found so that finally a relation between the flow resistance coefficient $C_{d}$ and the Reynolds number $R_{e}$ could be obtained. The values of resistance coefficient for variant I and II were averaged for the analyzed range of Reynolds number (horizontal lines in Figure 8). As follows from the results, for each tree species the flow resistance coefficient is greater for the natural trunk than for the trunk wrapped in foil (Figure 8).

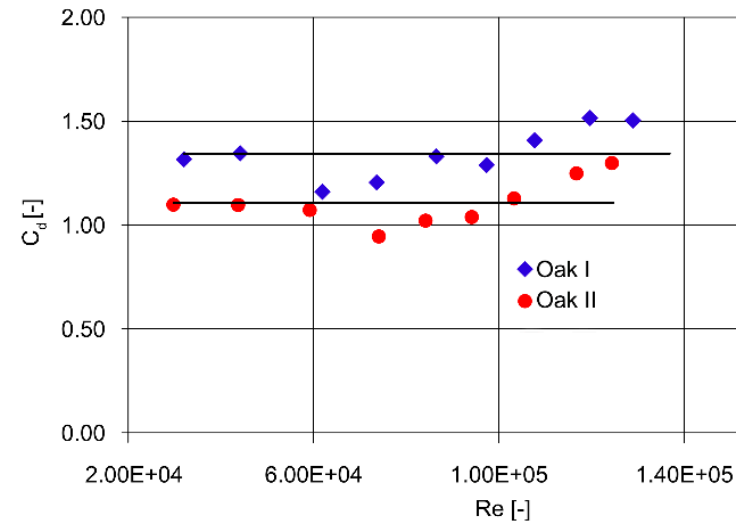

(A)

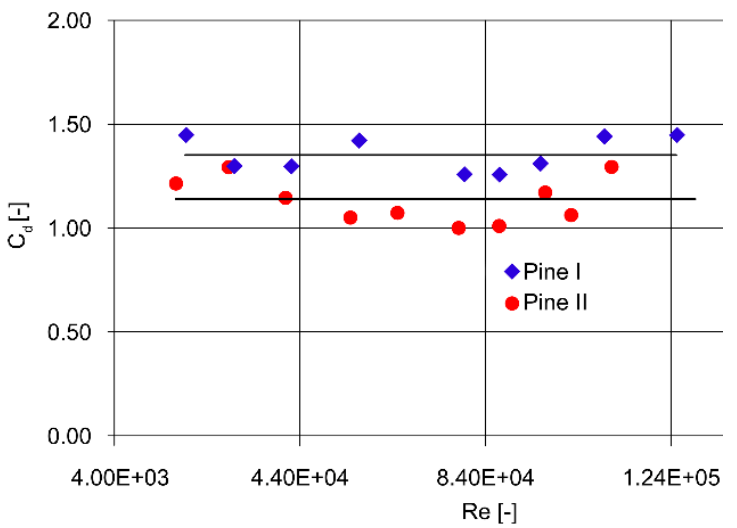

(B)

Figure 8. Flow resistance coefficient $C_{d}$ versus Reynolds number Re for oak (A) and pine (B).

The flow resistance coefficient calculated on the basis of average values is higher for the natural than for the foil-wrapped tree trunk, by about $22 \%$. For $R_{e}>10^{5}$ the values of the flow resistance coefficient increase for the natural trunk and that wrapped in foil to the values of 1.50 and 1.30, respectively. Mean value of $C_{d}$ for Oak I equals 1.35 and for Oak II 1.11. The bark structure of the natural oak tree trunk is responsible for the flow resistance coefficient increase by about $20 \%$ with respect to that for the trunk wrapped in foil. Similar results were obtained for Pine. The mean value of $C_{d}$ for Pine I equals 1.35 and for Pine II 1.13. In this case, the increase of BHF for natural tree trunk equals 20\% (Table 4). The largest absolute differences between the values of $C_{d}$ occurred in the case of pine and amounted to 0.38 . Table 4 also presents the percentage increase in $C_{d}$ for the natural stem related to foil wrapped.

Table 4. Comparison of results flow resistance coefficient $C_{d}$ for oak and pine.

\begin{tabular}{cccccccccc}
\hline \multicolumn{3}{c}{ Oak } & \multicolumn{3}{c}{ Pine } \\
\hline $\boldsymbol{R}_{\boldsymbol{e}}$ & $\boldsymbol{C}_{\boldsymbol{d I}}$ & $\boldsymbol{C}_{\boldsymbol{d I I}}$ & $\Delta \boldsymbol{C}_{\boldsymbol{d}}$ & $\%$ & $\boldsymbol{R}_{\boldsymbol{e}}$ & $\boldsymbol{C}_{\boldsymbol{d I}}$ & $\boldsymbol{C}_{\boldsymbol{d I I}}$ & $\Delta \boldsymbol{C}_{\boldsymbol{d}}$ & $\%$ \\
\hline $3.19 \times 10^{4}$ & 1.32 & 1.10 & 0.22 & 20 & $1.71 \times 10^{4}$ & 1.44 & 1.21 & 0.24 & 20 \\
$4.42 \times 10^{4}$ & 1.35 & 1.10 & 0.25 & 23 & $2.84 \times 10^{4}$ & 1.30 & 1.29 & 0.01 & 1 \\
$6.17 \times 10^{4}$ & 1.16 & 1.07 & 0.09 & 8 & $4.08 \times 10^{4}$ & 1.30 & 1.14 & 0.16 & 14 \\
$7.34 \times 10^{4}$ & 1.21 & 0.95 & 0.26 & 28 & $5.47 \times 10^{4}$ & 1.42 & 1.05 & 0.37 & 35 \\
$8.64 \times 10^{4}$ & 1.33 & 1.03 & 0.31 & 30 & $6.48 \times 10^{4}$ & 1.30 & 1.07 & 0.23 \\
$9.71 \times 10^{4}$ & 1.30 & 1.04 & 0.26 & 25 & $7.80 \times 10^{4}$ & 1.26 & 1.00 & 0.26 & 26 \\
$1.08 \times 10^{5}$ & 1.41 & 1.13 & 0.28 & 25 & $8.65 \times 10^{4}$ & 1.26 & 1.01 & 0.25 & 25 \\
$1.20 \times 10^{5}$ & 1.52 & 1.25 & 0.27 & 22 & $9.66 \times 10^{4}$ & 1.31 & 1.17 & 0.15 & 12 \\
$1.37 \times 10^{5}$ & 1.52 & 1.30 & 0.22 & 17 & $1.02 \times 10^{5}$ & 1.44 & 1.06 & 0.38 & 35 \\
$1.29 \times 10^{5}$ & 1.51 & 1.29 & 0.22 & 17 & $1.11 \times 10^{5}$ & 1.45 & 1.29 & 0.16 & 12 \\
\hline
\end{tabular}




\section{Discussion}

An increase in knowledge about simple and complex canopy roughness for various types of vegetation is necessary, especially when considering overall roughness inputs in hydraulic modeling. The study conducted by Antonarakis et al. [28] aimed to determine stem roughness friction factors for the below-canopy flow; for this reason they used such parameters of trees as trunk location, height, and diameter. Total height-derived trunk diameters using the tree detection and crown segmentation (TDCS) method produced the closest roughness coefficient values to the ground-derived roughness coefficients. The stem roughness values produced from this method fell within guideline values. Studies performed to date on the use of TLS have mainly concerned the 3D bark texture analysis and have been used for identification of tree species [27,30,36,37]. The results of this study have shown the potential of GIS tools and TLS data for analysis of bark structure characteristics of tree trunks in floodplains. In particular, high resolution of the point clouds permits advanced analyses, including that of the tree trunk texture. The possibility to determine the bark structure characteristics supplements the already proven applications of TLS demonstrated by Kankare et al. [34] and Hyyti and Visala [35], for determination of the diameter at breast height $(D B H)$, tree heights, wood volume, tree stem ovality, structure and damage of bark, tree topology, and branch angles and diameters. Determination of the bark structure characteristics of trees permits a more accurate evaluation of the roughness coefficients of floodplains. As demonstrated by Antonarakis et al. [16], tree trunks are major contributors to roughness in a densely wooded floodplain. The proposed method for determination of bark structure characteristics can be used in the field, and meets the requirements defined by Tanaka et al. [19], according to which the measurement of canopy structure must be nondestructive.

Dassot et al. [45] and Kükenbrink et al. [46] have shown that evaluation of the flow resistance of vegetation requires the millimeter resolution. The use of ALS data in this case is impossible [48]. Only the use of TLS measurements permits construction of high-resolution models of tree trunks and their parametrization (determination of the bark structure characteristics and their changes along the tree trunk). According to Tanaka et al. [44], it is very important to determine the drag characteristics of real tree trunks with various barks. The developed Tree Trunk Bark Structure Model can be commonly used for all tree species. This research also demonstrates the ability of terrestrial scanning in ideal laboratory conditions to extract meaningful information about the tree trunk. To estimate bark structure characteristics of the tree trunk in the field, optimal scanning conditions must be ensured. During the laboratory measurements there were ideal conditions for scanning and the distance from the scanner to the tree trunks was up to $2.5 \mathrm{~m}$. Locating the scanner at a greater distance while maintaining the same scan quality may only allow for determining the location of individual trees and estimating the trunk diameter. As Brolly and Király [27] suggested, the tree diameters determined on the basis of laser scanning may be different than the real ones, especially in the case of rough barked and noncircular stem cross-section trees. The methodology presented in this study should be verified in the field on different tree species with varying age. According to Othmani et al. [36], it will help to standardize the tree to a scanner distance that has an impact on the resolution of the point cloud in order to obtain point clouds of sufficiently good resolution in a reasonable time. Othmani et al. [30] demonstrated that scanning a tree with a diameter of about $30 \mathrm{~cm}$ with a TLS at $6 \mathrm{~m}$ allows for the analysis of the $3 \mathrm{D}$ geometric texture of the bark in order to compute roughness measures and shape characteristics. The methods presented in this study may have limitations in in situ measurement, with the first being the quality of the scanner data. Antonarakis et al. [26] suggested that the issue with the methods derived from the ground scanning data was a combination of two factors. The first was the effect of the wind on the scanning of the objects, and the second was the points reflected from the edges of objects. Another factor that may influence the result of the proposed method in the field is, according to Brolly and Király [27], to assure optimal conditions for scanning the leaf-off state, the lack of shrubs, the high crown bases, and the moderate terrain variability.

Our results showed that the tree trunk bark structure increases the flow resistance of trees by about $20 \%$ compared to tree trunks wrapped in foil. It should be stated that these are preliminary 
results, based only on two tree trunks, which can only show that bark structure impact in hydraulic modeling should not be neglected. The presented methodology may be useful for the study of different trees of the same and different species in order to determine the impact of bark structure on the flow resistance coefficient more accurately. The universal character of the method proposed means that it can be applied in a wider range, defined by Tanaka et al. [44], for analysis of vertical stand structure of trunk and branches.

The experimentally determined coefficients of flow resistance for the tree trunks wrapped in foil take values similar to that obtained by Schlichting and Gersten [49], which was $C_{d}=1.1$, for smooth tree trunks for the Reynolds number $3 \cdot 10^{4}<R_{e}<10^{5}$ (Figures 9 and 10). The natural trunks, both oak and pine, achieved larger values of $C_{d}$. This shows that not taking into account the bark characteristics may lead to underestimating of $C_{d}$ and further on lowering the value of friction factor (Equation (1)). The figures also show that the conducted research covers only on certain range of $R_{e}$ values. However, it is particularly interesting from the point of view of average conditions occurring during floods when water may flow in areas covered with trees (velocities $0.1-0.5 \mathrm{~m} / \mathrm{s}$ ).

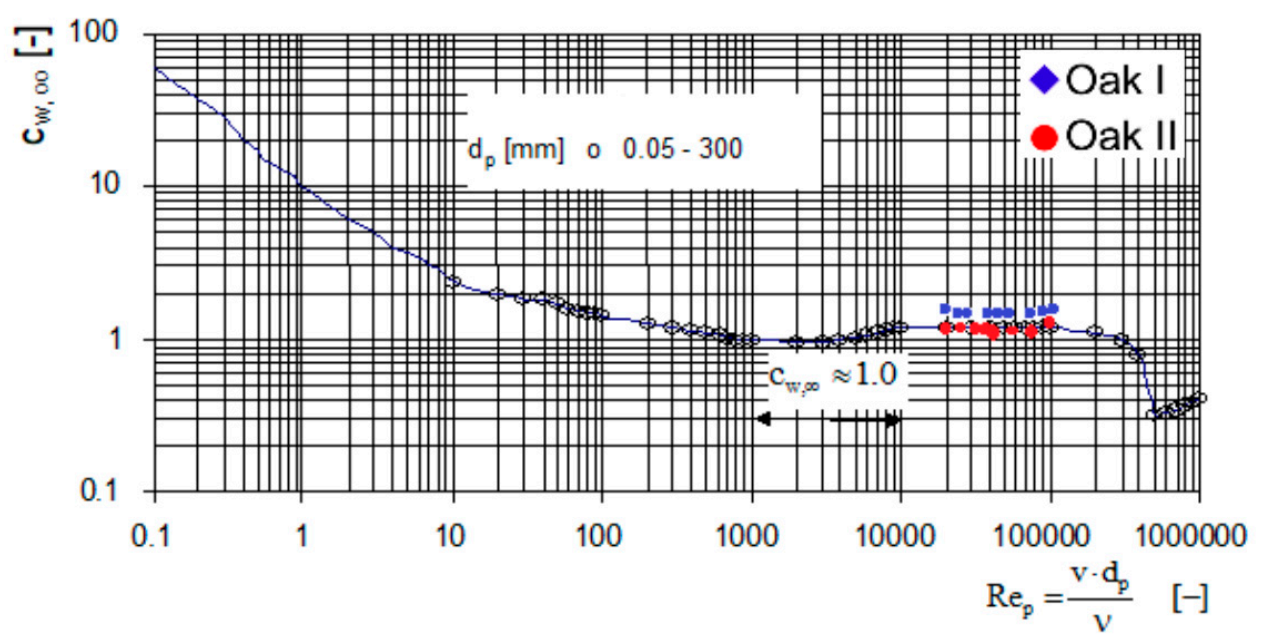

Figure 9. Flow resistance coefficient $C_{d}$ versus Reynolds number $R_{e}$ for oak against the $C_{d}=\mathrm{f}\left(R_{e}\right)$ [49].

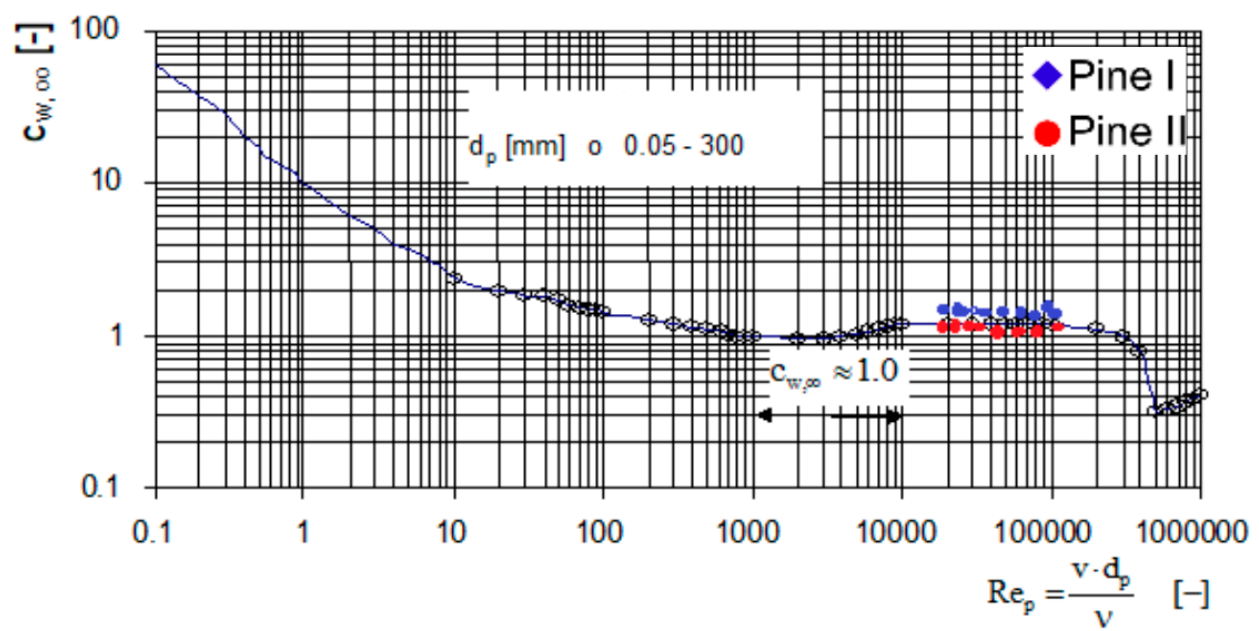

Figure 10. Flow resistance coefficient $C_{d}$ versus Reynolds number Re for pine against the $C_{d}=\mathrm{f}$ $\left(R_{e}\right)[49]$.

In the same paper [49], it was assumed that the contribution of the tree trunk roughness to the total flow resistance of a smooth cylinder is $11 \%$, so it can be neglected; however, the laboratory tests 
performed by us indicated that this contribution is much greater and reaches $20 \%$. Similar results were obtained by Ruck et al. [50], who studied the flow around the cylinder with increased roughness. The used roughness varied according to the layer thickness of balls coated on the cylinder. Three different layer thicknesses were tested: 3, 5, and $10 \mathrm{~mm}$. For both experimental series, the Reynolds number was systematically varied in the range from $1.0 \cdot 10^{4}$ to $1.3 \cdot 10^{5}$. The drag coefficients obtained in research seem to be quite constant in the investigated range of Reynolds numbers. The drag coefficients of the fully coated cylinders are $15-25 \%$ higher than for the smooth cylinder. Obviously, the drag increases with increasing layer thickness. Values obtained in our research for natural stems were similar for $B H F$ ranging from 3 to $10 \mathrm{~mm}$. This confirmed the importance of this parameter on the coefficient of resistance to the flow of tree trunks.

\section{Conclusions}

The overall scope of this modeling exercise was to illustrate the effects of tree trunk bark structure on flow resistance coefficient. This was achieved by comparing a natural and foil-wrapped tree trunk. A combination of the capabilities of GIS tools and TLS technique offers great possibilities of advanced measurements and analyses. Terrestrial laser scanning has been used in this study to define tree trunk bark at a millimeter resolution for the purpose of parameterizing bark structure in resistance equations.

The presented method of TLS scanning resulted in a high resolution of the point clouds, reaching 50 points $/ \mathrm{cm}^{2}$, which allows for the development of highly detailed 3D models that can be used for analyzing tree trunk structure. The developed TTBSM model allows one to automate the process of calculating the bark characteristics of tree trunks based on the TLS data. The model can be used to analyze various species of trees of different ages.

For the natural tree trunks, the average $B H F$ of the pine trunk was greater, $0.41 \mathrm{~cm}$, while that of the oak trunk was $0.37 \mathrm{~cm}$. As follows from the analysis of bark structure characteristics of tree trunks along their length, the variation of this parameter was observed. The analysis of pine and oak trunks indicates the greatest differences between average slope, $2 \mathrm{D}$ to $3 \mathrm{D}$ area ratio and BHF in the bottom part. The surface of the oak tree trunk was most uniform and was characterized by the lowest spatial variation of slopes, 2D to 3D area ratios and roughness. Analysis of BHF parameters of the foil-wrapped tree trunks, performed over segments of $0.05 \mathrm{~m}$, indicate that for pine the values were slightly higher than in oak, from 0.01 to $0.03 \mathrm{~cm}$.

The results presented and discussed above have proved that the bark structure of tree trunks has a significant impact on the flow resistance of trees. For the pine and oak tree trunks studied, the coefficient of flow resistance $C_{d}$ for the natural trunks was on average $20 \%$ higher than that for the trunks wrapped in foil. We have shown that the impact of the tree trunk bark structure analyzed with respect to the impact of the shape of the body (cylinder) on the coefficient of flow resistance $C_{d}$ is greater than it has been hitherto assumed on the basis of literature data. The ratio of 20 to $80 \%$ is significantly different than the literature ratio of 10 to $90 \%$. In view of that, the assumption that the effect of bark structure of tree trunks can be neglected is unfounded and can lead to a considerable error in the evaluation of flow conditions in forested floodplains.

Author Contributions: T.K. and M.S. formulated the concept. P.S. was responsible for tree trunk scanning and data preprocessing. R.W. and M.S. developed the Tree Trunk Bark Structure Model (TTBSM) operating in the ArcGIS environment and conducted statistical analysis. T.K. conducted the analysis between flow resistance of trees and bark structure. All authors contributed in manuscript writing.

Funding: This research was funded by the Poznań University of Life Sciences.

Conflicts of Interest: The authors declare no conflicts of interest. 


\section{References}

1. Baptist, M.J.; Babovic, V.; Rodríguez Uthurburu, J.; Keijzer, M.; Uittenbogaard, R.E.; Mynett, A.; Verwey, A. On inducing equations for vegetation resistance. J. Hydraul. Res. 2007, 45, 435-450. [CrossRef]

2. Horritt, M.S. A methodology for the validation of uncertain flood inundation models. J. Hydrol. 2006, 326, 153-165. [CrossRef]

3. Klopstra, D.; Barneveld, H.J.; van Noortwijk, J.; van Velzen, E. Analytical model for hydraulic roughness of submerged vegetation. In Proceedings of the 27th IAHR Conference, San Francisco, CA, USA, 10-15 August 1997; American Society of Civil Engineers (ASCE): New York, NY, USA, 1997; pp. 775-780.

4. $\mathrm{Wu}, \mathrm{Y}$; Falconer, R.A.; Struve, J. Mathematical modelling of tidal currents in mangrove forests. Environ. Model. Softw. 2001, 16, 19-29. [CrossRef]

5. Yang, W.; Choi, S.U. A two-layer approach for depth-limited open-channel flows with submerged vegetation. J. Hydraul. Res. 2010, 48, 466-475. [CrossRef]

6. Crosato, A.; Saleh, M.S. Numerical study on the effects of floodplain vegetation on river planform style. Earth Surf. Proc. Landf. 2011, 36, 711-720. [CrossRef]

7. Perona, P.; Camporeale, C.; Perucca, E.; Savina, M.; Molnar, P.; Burlando, P.; Ridolfi, L. Modelling river and riparian vegetation interactions and related importance for sustainable ecosystem management. Aquat. Sci. 2009, 71, 266. [CrossRef]

8. Velasco, D.; Bateman, A.; Medina, V. A new integrated, hydro-mechanical model applied to flexible vegetation in riverbeds. J. Hydraul. Res. 2008, 46, 579-597. [CrossRef]

9. Meijer, D.G.; Van Velzen, E.H. Prototype-scale flume experiments on hydraulic roughness of submerged vegetation. In Proceedings of the 28th International IAHR Conference, Graz, Austria, 22-27 August 1999; Technical University Graz, Institute for Hydraulics and Hydrology: Graz, Austria, 1999.

10. Murphy, E.; Ghisalberti, M.; Nepf, H. Model and laboratory study of dispersion in flows with submerged vegetation. Water Resour. Res. 2007, 43. [CrossRef]

11. Tal, M.; Paola, C. Effects of vegetation on channel morphodynamics: Results and insights from laboratory experiments. Earth Surf. Proc. Landf. 2010, 35, 1014-1028. [CrossRef]

12. Straatsma, M. 3D float tracking: In situ floodplain roughness estimation. Hydrol. Process. 2009, 23, $201-212$. [CrossRef]

13. Walczak, Z.; Sojka, M.; Wróżyński, R.; Laks, I. Estimation of Polder Retention Capacity Based on ASTER, SRTM and LIDAR DEMs: The Case of Majdany Polder (West Poland). Water 2016, 8, 230. [CrossRef]

14. Laks, I.; Sojka, M.; Walczak, Z.; Wróżyński, R. Possibilities of Using Low Quality Digital Elevation Models of Floodplains in Hydraulic Numerical Models. Water 2017, 9, 283. [CrossRef]

15. Forzieri, G.; Degetto, M.; Righetti, M.; Castelli, F.; Preti, F. Satellite multispectral data for improved floodplain roughness modelling. J. Hydrol. 2011, 407, 41-57. [CrossRef]

16. Antonarakis, A.S.; Richards, K.S.; Brasington, J.; Muller, E. Determining leaf area index and leafy tree roughness using terrestrial laser scanning. Water Resour. Res. 2010, 46. [CrossRef]

17. Petryk, S.; Bosmajian, G., III. Analysis of flow through vegetation. J. Hydraul. Div. 1975, 101, 871-884.

18. Arcement, G.J.; Schneider, V.R. Guide for Selecting Manning's Roughness Coefficients for Natural Channels and Flood Plains; U.S. Geological Survey: Denver, CO, USA, 1989.

19. Tanaka, T.; Yamaguchi, J.; Takeda, Y. Measurement of forest canopy structure with a laser plane range-finding method-Development of a measurement system and applications to real forests. Agric. For. Meteorol. 1998, 91, 149-160. [CrossRef]

20. Lindner, K. Der Strömungswiderstand von Pflanzenbeständen; Mitteilungen; Heft 75; Technische Universität Braunschweig; Leichtweiss-InstitutfürWasserbau: Braunschweig, Germany, 1982.

21. Nakayama, A. Introduction to Fluid Mechanics; Butterworth-Heinemann: Oxford, UK, 1999.

22. Aberle, J.; Järvelä, J. Flow resistance of emergent rigid and flexible floodplain vegetation. J. Hydraul. Res. 2013, 51, 33-45. [CrossRef]

23. Straatsma, M.W.; Baptist, M.J. Floodplain roughness parameterization using airborne laser scanning and spectral remote sensing. Remote Sens. Environ. 2008, 112, 1062-1080. [CrossRef]

24. Casas, A.; Lane, S.N.; Yu, D.; Benito, G. A method for parameterising roughness and topographic sub-grid scale effects in hydraulic modelling from LiDAR data. Hydrol. Earth Syst. Sci. 2010, 14, 1567-1579. [CrossRef] 
25. Shendryk, I.; Broich, M.; Tulbure, M.G.; Alexandrov, S.V. Bottom-up delineation of individual trees from full-waveform airborne laser scans in a structurally complex eucalypt forest. Remote Sens. Environ. 2016, 173, 69-83. [CrossRef]

26. Antonarakis, A.S.; Richards, K.S.; Brasington, J.; Bithell, M. Leafless roughness of complex tree morphology using terrestrial lidar. Water Resour. Res. 2009, 45. [CrossRef]

27. Brolly, G.; Király, G. Algorithms for stem mapping by means of terrestrial laser scanning. Acta Silvatica et Lignaria Hungarica 2009, 5, 119-130.

28. Antonarakis, A.S.; Richards, K.S.; Brasington, J.; Bithell, M.; Muller, E. Retrieval of vegetative fluid resistance terms for rigid stems using airborne lidar. J. Geophys. Res. Biogeosci. 2008, 113. [CrossRef]

29. Lovell, J.L.; Jupp, D.L.B.; Newnham, G.J.; Culvenor, D.S. Measuring tree stem diameters using intensity profiles from ground-based scanning lidar from a fixed viewpoint. ISPRS J. Photogramm. Remote Sens. 2011, 66, 46-55. [CrossRef]

30. Othmani, A.; Piboule, A.; Dalmau, O.; Lomenie, N.; Mokrani, S.; Voon, Y. Tree species classification based on 3D bark texture analysis. In Proceedings of the Pacific-Rim Symposium on Image and Video Technology; Springer: Berlin, Germany, 2013; pp. 279-289.

31. Bienert, A.; Maas, H.G.; Scheller, S. Analysis of the information content of terrestrial laser scanner point clouds for the automatic determination of forest inventory parameters. In Proceedings of the Workshop on 3D Remote Sensing in Forestry, Vienna, Austria, 14-15 February 2006; Volume 14, pp. 1-7.

32. Yang, X.; Strahler, A.H.; Schaaf, C.B.; Jupp, D.L.; Yao, T.; Zhao, F.; Dubayah, R.O. Three-dimensional forest reconstruction and structural parameter retrievals using a terrestrial full-waveform lidar instrument (Echidna ${ }^{\circledR}$ ). Remote Sens. Environ. 2013, 135, 36-51. [CrossRef]

33. Wang, D.; Hollaus, M.; Puttonen, E.; Pfeifer, N. Fast and robust stem reconstruction in complex environments using terrestrial laser scanning. Int. Arch. Photogramm. Remote Sens. Spat. Inf. Sci. 2016, 41, 411-417. [CrossRef]

34. Kankare, V.; Holopainen, M.; Vastaranta, M.; Puttonen, E.; Yu, X.; Hyyppä, J.; Alho, P. Individual tree biomass estimation using terrestrial laser scanning. ISPRS J. Photogramm. Remote Sens. 2013, 75, 64-75. [CrossRef]

35. Hyyti, H.; Visala, A. Feature Based modeling and mapping of tree trunks and natural terrain using 3D laser scanner measurement system. IFAC Proc. Vol. 2013, 46, 248-255. [CrossRef]

36. Othmani, A.A.; Jiang, C.; Lomenie, N.; Favreau, J.M.; Piboule, A.; Voon, Y. A novel computer-aided tree species identification method based on burst wind segmentation of 3D bark textures. Mach. Vis. Appl. 2016, 27, 751-766. [CrossRef]

37. Lin, Y.; Herold, M. Tree species classification based on explicit tree structure feature parameters derived from static terrestrial laser scanning data. Agric. For. Meteorol. 2016, 216, 105-114. [CrossRef]

38. Hosoi, F.; Omasa, K. Voxel-based 3-D modeling of individual trees for estimating leaf area density using high-resolution portable scanning lidar. IEEE Trans. Geosci. Remote Sens. 2006, 44, 3610-3618. [CrossRef]

39. Calders, K.; Armston, J.; Newnham, G.; Herold, M.; Goodwin, N. Implications of sensor configuration and topography on vertical plant profiles derived from terrestrial LiDAR. Agric. For. Meteorol. 2014, 194, 104-117. [CrossRef]

40. Calders, K.; Newnham, G.; Burt, A.; Murphy, S.; Raumonen, P.; Herold, M.; Kaasalainen, M. Nondestructive estimates of above-ground biomass using terrestrial laser scanning. Methods Ecol. Evol. 2015, 6, 198-208. [CrossRef]

41. Sioma, A.; Socha, J.; Klamerus-Iwan, A. A New Method for Characterizing Bark Microrelief Using 3D Vision Systems. Forests 2018, 9, 30. [CrossRef]

42. Westoby, M.J.; Brasington, J.; Glasser, N.F.; Hambrey, M.J.; Reynolds, J.M. 'Structure-from-Motion' photogrammetry: A low-cost, effective tool for geoscience applications. Geomorphology 2012, 179, 300-314. [CrossRef]

43. Wróżyński, R.; Pyszny, K.; Sojka, M.; Przybyła, C.; Murat-Błażejewska, S. Ground volume assessment using 'Structure from Motion' photogrammetry with a smartphone and a compact camera. Open Geosci. 2017, 9, 281-294. [CrossRef]

44. Tanaka, N.; Takenaka, H.; Yagisawa, J.; Morinaga, T. Estimation of drag coefficient of a real tree considering the vertical stand structure of trunk, branches, and leaves. Int. J. River Basin Manag. 2011, 9, 221-230. [CrossRef] 
45. Dassot, M.; Colin, A.; Santenoise, P.; Fournier, M.; Constant, T. Terrestrial laser scanning for measuring the solid wood volume, including branches, of adult standing trees in the forest environment. Comput. Electron. Agric. 2012, 89, 86-93. [CrossRef]

46. Kükenbrink, D.; Schneider, F.D.; Leiterer, R.; Schaepman, M.E.; Morsdorf, F. Quantification of hidden canopy volume of airborne laser scanning data using a voxel traversal algorithm. Remote Sens. Environ. 2017, 194, 424-436. [CrossRef]

47. ASME. Surface Texture (Surface Roughness, Waviness, and Lay): An American Standard; ASME B46.1-1995 (Revision of ANSI/ASME B46.1-1985); ASME: New York, NY, USA, 1996.

48. Walczak, Z.; Sojka, M.; Laks, I. Assessment of mapping of embankments and control structure on digital elevation model based up on Majdany polder. Rocznik Ochrona Srodowiska 2013, 15, 2711-2724.

49. Schlichting, H.; Gersten, K. Grenzschicht-Theorie; Springer: Berlin/Heidelberg, Germany, 2006.

50. Ruck, B.; Klausmann, K.; Wacker, T. Drag reduction of cylinders by partial porous coating. In Proceedings of the 9th International Conference on Heat Transfer, Fluid Mechanics and Thermodynamics, Malta, 16-18 July 2012.

2018 by the authors. Licensee MDPI, Basel, Switzerland. This article is an open access article distributed under the terms and conditions of the Creative Commons Attribution (CC BY) license (http:/ / creativecommons.org/licenses/by/4.0/). 